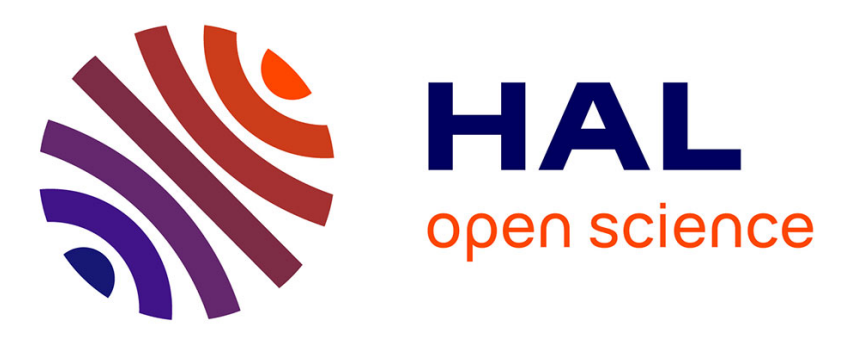

\title{
Efficacy and safety of atomoxetine as add-on to psychoeducation in the treatment of attention deficit/hyperactivity disorder
}

Pär Svanborg, Gunilla Thernlund, Per A. Gustafsson, Bruno Hägglöf, Lynne Poole, Björn Kadesjö

\section{To cite this version:}

Pär Svanborg, Gunilla Thernlund, Per A. Gustafsson, Bruno Hägglöf, Lynne Poole, et al.. Efficacy and safety of atomoxetine as add-on to psychoeducation in the treatment of attention deficit/hyperactivity disorder. European Child and Adolescent Psychiatry, 2009, 18 (4), pp.240-249. 10.1007/s00787-0080725-5 . hal-00478076

\section{HAL Id: hal-00478076 https://hal.science/hal-00478076}

Submitted on 30 Apr 2010

HAL is a multi-disciplinary open access archive for the deposit and dissemination of scientific research documents, whether they are published or not. The documents may come from teaching and research institutions in France or abroad, or from public or private research centers.
L'archive ouverte pluridisciplinaire HAL, est destinée au dépôt et à la diffusion de documents scientifiques de niveau recherche, publiés ou non, émanant des établissements d'enseignement et de recherche français ou étrangers, des laboratoires publics ou privés. 
Pär Svanborg

Gunilla Thernlund

Per A. Gustafsson

Bruno Hägglöf

Lynne Poole

Björn Kadesjö
Efficacy and safety of atomoxetine as add-on to psychoeducation in the treatment of attention deficit/hyperactivity disorder

\author{
A randomized, double-blind, placebo-controlled \\ study in stimulant-naïve Swedish children \\ and adolescents
}

Received 4 December 2007

Accepted: 10 August 2008

Published online: 20 January 2009

Dr. P. Svanborg $(\bowtie)$

Eli Lilly Sweden AB

Gustav III Boulevard 42

Box 721, 16927 Solna, Sweden

Tel.: +46-706098893

Fax: +46-86182150

E-Mail: svanborg_par@lilly.com

and

Department of Clinical Neuroscience

Psychiatry Section

Karolinska Institutet

17176 Stockholm, Sweden

G. Thernlund

Department of Child and Adolescent

Psychiatry

Clinical Sciences

Lund University

22185 Lund, Sweden

P.A. Gustafsson

Child and Adolescent Psychiatry (BUP)

University Hospital

58185 Linköping, Sweden

B. Hägglöf

Unit of Child and Adolescent Psychiatry

NUS, Bu 23

Umeå University

90187 Umeå, Sweden

L. Poole

Employed by Eli Lilly \& Co. at the

time the research was performed

B. Kadesjö

Department of Child and Adolescent

Psychiatry

University of Gothenburg

Drottning Silvias Barnsjukhus

Barnneuropsykiatriska kliniken (BNK)

ㄱ 41118 Göteborg, Sweden
Abstract Objective The primary objective of this study was to assess the impact of atomoxetine in combination with psychoeducation, compared with placebo and psychoeducation, on health-related quality of life (HRQL) in Swedish stimulant-naïve pediatric patients with attention deficit/hyperactivity disorder (ADHD). HRQL results will be presented elsewhere. Here, psychoeducation as well as efficacy and safety of the treatment are described. Patients and methods A total of 99 pediatric ADHD patients were randomized to a 10-week doubleblind treatment with atomoxetine (49 patients) or placebo (50 patients). Parents of all patients received four sessions of psychoeducation. Atomoxetine was dosed up to approximately $1.2 \mathrm{mg} / \mathrm{kg}$ day $(\leq 70 \mathrm{~kg})$ or $80 \mathrm{mg} /$ day $(>70 \mathrm{~kg})$. Improvement of ADHD symptoms was evaluated using the ADHD rating scale (ADHD-RS) and clinical global impression (CGI) rating scales. Safety was assessed based on adverse events (AEs). Results The study population was predominantly male $(80.8 \%)$ and diagnosed with the combined ADHD subtype (77.8\%). The least square mean (lsmean) change from baseline to endpoint in total ADHD-RS score was - 19.0 for atomoxetine patients and -6.3 for placebo patients, resulting in an effect size (ES) of 1.3 at endpoint. Treatment response (reduction in ADHD-RS score of $\geq 25$ or $\geq 40 \%$ ) was achieved in 71.4 or $63.3 \%$ of atomoxetine patients and 28.6 or $14.3 \%$ of placebo patients. The lsmean change from baseline to endpoint in CGISeverity was -1.8 in the atomoxetine group compared with -0.3 in the placebo group. The difference between treatments in CGIImprovement at endpoint was -1.4 in favor of atomoxetine. No serious AEs occurred. The safety profile of atomoxetine was in line with the current label. Conclusions Atomoxetine combined with psychoeducation was superior to placebo and psychoeducation in ADHD core symptoms improvement. The large ES might be a result of including stimulantnaïve patients only, but also may indicate a positive interaction between atomoxetine treatment and psychoeducation, possibly by increased compliance.

Key words ADHD atomoxetine - clinical research/ trial - parenting education pharmacotherapy 
Abbreviations ADHD: Attention deficit/hyperactivity disorder, ADHDRS: Attention deficit/hyperactivity disorder rating scale, AE: Adverse event, ANCOVA: Analysis of covariance, ANOVA: Analysis of variance, CD: Conduct disorder, CGI-I: Clini- cal global impression-improvement, CGI-S: Clinical global impressionseverity, DSM-IV: Diagnostic and statistical manual of mental disorders, 4th edition, ES: Effect size, K-SADS-PL: Kiddie schedule for affective disorders and schizophre- nia for school-age children-present and lifetime version, LOCF: Last observation carried forward, MMRM: Mixed-model repeated measures, ODD: Oppositional defiant disorder, HRQL: Health-related quality of life

\section{Introduction}

Attention deficit/hyperactivity disorder (ADHD) is the most commonly diagnosed neurodevelopmental disorder in children and adolescents, with 3-8\% of all school-aged children being affected $[1,2]$. ADHD is often associated with prominent psychiatric co-morbidities, such as oppositional defiant disorder (ODD), conduct disorder, tics and sleep disorders, learning disorder, and motor problems [3-5]. Children and adolescents with ADHD are at high risk for a wide range of adverse psychiatric outcomes including markedly elevated rates of antisocial, addictive, mood and anxiety disorders [6], and frequently suffer from impairment in school performance, family and peer relations, and higher proneness for injury, which leads to poor health related quality of life (HRQL) $[7,8]$.

Current treatments include pharmacotherapy, behavioral, and psychosocial interventions [9]. In 2002, atomoxetine was approved in the US as the first non-stimulant compound for treatment of ADHD. Compared with stimulants, atomoxetine has a relatively slow onset of action (days-weeks compared with minutes-hours) $[7,10]$. Administered once-daily in the morning, it provides continuous symptom relief that lasts not only into the evening hours but also into the morning hours [11]. Atomoxetine was proven to be a well-tolerated and efficacious treatment for ADHD in the first six acute placebo-controlled studies, in which it was always statistically superior to placebo [11-15]. Currently it presents by far the most extensively studied pharmacotherapeutic drug in clinical trials on children with ADHD [16]. Meanwhile atomoxetine is approved in most European countries for treatment of pediatric and adolescent ADHD patients.

The primary objective of the present study was to explore the changes in HRQL, or the "broader efficacy", of atomoxetine compared with placebo in Swedish children and adolescents, primarily measured by the Children's Health and Illness Profile, Child Edition, Parent Reported (CHIP-CE) [17, 18]. These results will be reported separately. This manuscript will present and discuss the effect of atomoxetine combined with psychoeducation compared with placebo combined with psychoeducation on core ADHD symptoms and on safety measures in a stimulant-naïve population; in spite of the large number of placebo-controlled clinical trials with atomoxetine, no previous trial has included only stimulant-naïve patients. Inclusion of previously stimulant-treated patients may introduce heterogeneity in a study population that is difficult to control, since these patients (and/or their caregivers) are likely to be dissatisfied with at least some efficacy aspect or with the side effect profile of the previous treatment; thus they may represent a more treatment-resistant population. In addition, previously stimulant-treated patients and their caregivers are used to an almost instantaneous treatment effect and may therefore have very different expectations on the treatment effect of atomoxetine when compared with a treatmentnaïve population [19]. Consequently, study results obtained exclusively from stimulant-naïve patients are more likely to give an unbiased picture of the efficacy and safety of atomoxetine when given as a "first-line" treatment.

European regulatory authorities require a comprehensive treatment program for ADHD, which, in addition to the pharmacological treatment, includes psychological, educational and social measures [10]. To account for that, we developed a psychoeducational program which was mandatory for all patients' caregivers during the double-blind treatment phase.

\section{Methods}

\section{Study design}

This multi-center, randomized, double-blind, placebo-controlled, Phase 3b study (B4Z-SO-LY15) was conducted in Swedish pediatric ADHD patients. It was designed as a 3-period study, consisting of a screening period (study period I), a placebo-controlled, doubleblind treatment period (study period II), and an optional open-label long-term extension period (study period III). Results discussed here include study periods I and II only. 


\section{Study population and recruitment}

The study was conducted at nine outpatient investigative sites in Sweden. At Screening (visit 1), patients were assessed for eligibility. Male and female patients 7-15 years of age were included if they met the criteria for ADHD of the Diagnostic and Statistical Manual of Mental Disorders, Fourth Edition ${ }^{\mathrm{TM}}$ (DSM$I^{T M}$ ) and had a severity threshold of 1.5 standard deviations above the US age and gender norms for their diagnostic subtype on the ADHD rating scaleparent version: Investigator Administered and Scored. The diagnoses of ADHD and comorbidities were based on a clinical interview and confirmed by the Kiddie Schedule for Affective Disorders and Schizophrenia for School-Age Children-Present and Lifetime Version (K-SADS-PL [20]). The screening forms for affective (but not anxiety) and neuropsychiatric disorders were used for all patients, and a positive screening diagnosis was further confirmed by a more thorough interview, using the corresponding supplement. Eligible patients had to be stimulant-naïve. Important exclusion criteria included general impairment of intelligence, as clinically assessed by the investigator, serious medical illness, a history of psychosis or bipolar disorder, alcohol or drug abuse within the previous 3 months, or ongoing use of psychoactive medication other than the study drug. Patients who required immediate pharmacotherapy or structured psychotherapy were also excluded.

Prior to any study-related procedures, written informed consent was obtained from each patient's caregiver and written assent was obtained from the patients. The study was conducted in compliance with good clinical practice guidelines and in accordance with the ethical standards of the 1975 Declaration of Helsinki, as revised in 2002. The study protocol was reviewed and approved by the Ethical Review Board in Göteborg.

\section{Study treatments}

During the double-blind study period II, patients received either atomoxetine or placebo for 10 weeks. Randomization using an interactive voice system, stratified by site, was performed at visit 2 (week 0 ). Starting the day after visit 2, all patients took two capsules of study mediation in the morning. During week 1, atomoxetine patients weighing not more than $70 \mathrm{~kg}$ received a dose of $0.5 \mathrm{mg} / \mathrm{kg}$ day and patients weighing $>70 \mathrm{~kg}$ a dose of $40 \mathrm{mg} /$ day. After the first week, the dose was increased to $1.2 \mathrm{mg} / \mathrm{kg}$ day (weight of $\leq 70 \mathrm{~kg}$ ) or $80 \mathrm{mg} /$ day ( $>70 \mathrm{~kg}$ ). Atomoxetine capsules of $2.5,5,10,20,25$, and $40 \mathrm{mg}$ as well as identical placebo capsules were available in blister packs. Patients were assessed during study period II at weeks $1,3,5,7$, and 10 (visits 3-7).

In addition to pharmacotherapy, treatment included a psychoeducational program for the patients' caregivers of both treatment groups. This program, developed by a professional educational manager, consisted of four 3-h sessions and was specifically adapted to the conditions associated with this clinical study in children and adolescents. It aimed to improve the caregivers' knowledge and understanding of ADHD and the implications of the disorder on the child's everyday functioning, to increase the caregivers' awareness of how they can adjust the environment to the child's functional level, to provide guidance on how to facilitate and promote positive parent-child interaction and positive behavioral patterns, to give an introduction on how behavior modification principles can be applied in handling the child's problem behavior, and to guide and inform about available social and educational support and health care. Methods included introductory lectures, group discussions, problem solving, modeling, and role plays based on real life situations. Each session was conducted by one or two group leaders with various professional backgrounds (psychologists, social workers, special educators, and psychiatric nurses), who had broad experience with ADHD patients and were familiar with psychosocial treatment based on behavioral principles. All group leaders had to participate in a specific 2-day training supervised by the educational manager before the start of the trial. All information provided in slides and printed material was standardized, and all sites used the same educational material. After the last session, the caregivers received an evaluation form for assessment of the psychoeducational program. Although this evaluation was not planned in the study protocol and consequently not monitored by the study sponsor, the key findings will be presented here.

After completion of study period II, patients of both treatment groups were offered to enter the openlabel study period III extension, during which all patients received atomoxetine until it became commercially available in Sweden, but for no longer than 9 months.

\section{Assessments}

Efficacy on core ADHD symptoms was assessed using the ADHD rating scale-IV parent version (ADHD-RS), which evaluates all 18 symptoms of the DSM-IV ADHD diagnosis [21, 22]. An improvement is indicated by a decrease in scores. The original form was translated to Swedish, and then translated back to English. The Swedish translation then received ap- 
proval by the copyright holder (Guilford Press, New York, NY, USA). The ADHD-RS was applied and scored by qualified site personnel at each study visit. The inter-rater agreement was very high at a rater training session conducted prior to the start of the study (intraclass correlations coefficients of 0.82-1.0). Further efficacy assessments included the clinical global impression-severity (CGI-S) scale [23], a single-item expert rating of the severity of the patient's ADHD symptoms, and the clinical global impressionimprovement (CGI-I) scale [23], a single-item expert rating of the total improvement (or worsening) of the patient's symptoms since the beginning of treatment. CGI-S is rated on a seven-point scale, where $1=$ normal, not all at all, and $7=$ among the most extremely ill patients. CGI-I is rated on a seven-point scale, where $1=$ very much improved, $4=$ no change, and 7 = very much worsened. Safety was evaluated by monitoring adverse events (AEs) throughout the study. Compliance was assessed by direct questioning and upon review of returned medications and was defined as taking $70-130 \%$ of the study drug dosage prescribed for that particular visit interval.

\section{Analyses}

Sample size considerations were based on the primary objective of this study (HRQL as measured by the CHIP-CE Achievement domain) and will be reported with the respective results elsewhere. Demographics and baseline characteristics were summarized descriptively. Baseline was defined as the last assessment prior to or on the day of randomization (visit 2). For the efficacy variables ADHD-RS and CGI-S, the last observation carried forward (LOCF) change from baseline to endpoint (visit 7 at week 10) was analyzed using an analysis of covariance (ANCOVA) model including terms for baseline, treatment, and site. The endpoint value for CGI-I was analyzed using an analysis of variance (ANOVA) model including terms for treatment and site. In addition, a restricted maximum likelihood based mixed-model repeated measures (MMRM) model with terms for treatment, site, visit, and baseline (assuming no specific covariance structure) was applied for post-baseline scores using PROC MIXED in the SAS ${ }^{\circledR}$ software system. Further statistical tests included the t-test for continuous and Fisher's exact test for binary outcomes. All statistical significance tests were 2-sided with a nominal significance level of $5 \%$. The effect size (ES) was calculated by dividing the model based difference between the groups at each visit by the standard deviation of the corresponding residuals, and by using the LOCF change from baseline to endpoint ANCOVA.
All randomized patients who had at least a baseline and one post-baseline measurement in study period II were included in the efficacy analyses. Analysis of safety included all patients who took at least one dose of study medication.

\section{Results}

\section{Patients}

Of the 102 screened patients, 99 met the entry criteria and were randomized to atomoxetine (49 patients) or placebo (50 patients). All 99 patients completed the double-blind study period II and entered the openlabel study period III. The study cohort is summarized in Fig. 1. Both treatment groups were comparable in terms of demographics and baseline characteristics (Table 1).

\section{Medication and treatment compliance}

The mean doses prescribed at baseline were $0.7 \mathrm{mg} /$ $\mathrm{kg}(\mathrm{SD}=0.1)$, this increased to $1.2 \mathrm{mg} / \mathrm{kg}(\mathrm{SD}=0.2$, 0.1 ) at weeks 1 and 3 (visits 3,4 ) and $1.1 \mathrm{mg} / \mathrm{kg}$ $(\mathrm{SD}=0.2)$ for the final 5 weeks of double-blind treatment. The dose range during the last 7 weeks of the trial was $0.6-1.4 \mathrm{mg} / \mathrm{kg}$. Three atomoxetine-treated patients at week 5 and one atomoxetine-treated patient at week 7 needed dose adjustments (reduction

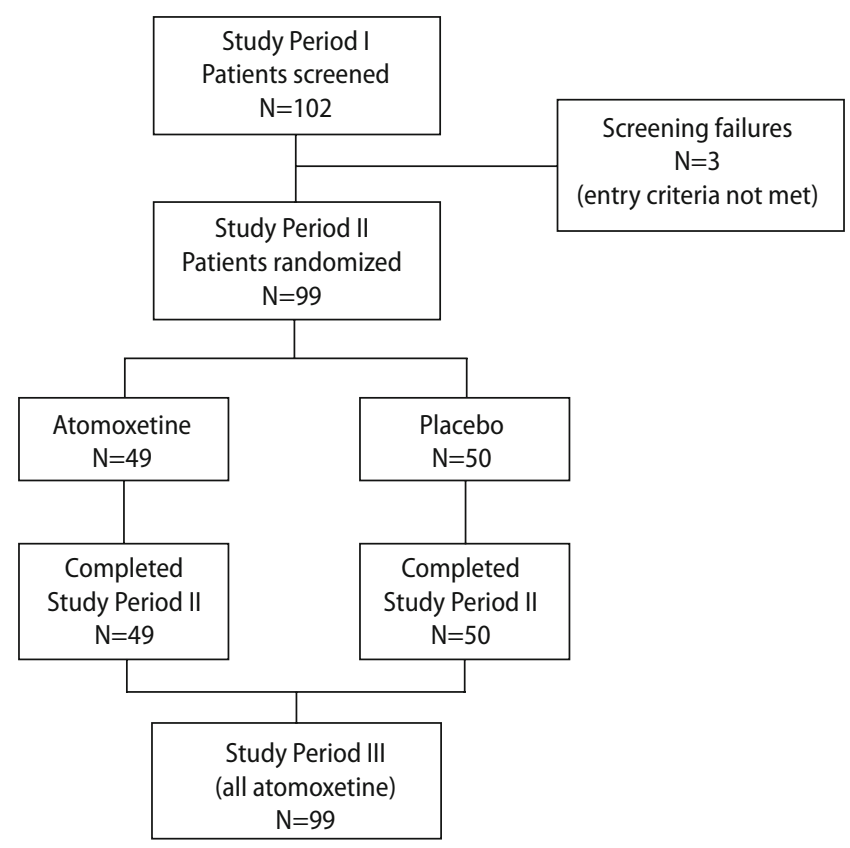

Fig. 1 Patient disposition flowchart 
Table 1 Demographics and baseline characteristics

\begin{tabular}{lccc}
\hline Parameter & $\begin{array}{c}\text { Atomoxetine } \\
(N=49)\end{array}$ & $\begin{array}{c}\text { Placebo } \\
(N=50)\end{array}$ & $\begin{array}{l}\text { Total } \\
(N=99)\end{array}$ \\
\hline $\begin{array}{l}\text { Gender } n(\%) \\
\text { Female }\end{array}$ & $10(20.4)$ & $9(18.0)$ & $19(19.2)$ \\
Male & $39(79.6)$ & $41(82.0)$ & $80(80.8)$ \\
Ethnic origin $n$ (\%) & & & \\
African & 0 & $1(2.0)$ & $1(1.0)$ \\
Caucasian & $44(89.8)$ & $49(98.0)$ & $93(93.9)$ \\
Asian & $3(6.1)$ & 0 & $3(3.0)$ \\
Other & $2(4.1)$ & 0 & $2(2.0)$ \\
Age group $n$ (\%) & & & \\
6-11 years & $24(49.0)$ & $32(64.0)$ & $56(56.6)$ \\
12-15 years & $25(51.0)$ & $18(36.0)$ & $43(43.4)$ \\
Mean Age (SD) years & $11.6(2.3)$ & $11.3(2.1)$ & $11.5(2.2)$ \\
DSM-IV ADHD subtype $n(\%)$ & & & \\
Combined & $37(75.5)$ & $40(80.0)$ & $77(77.8)$ \\
Hyperactive & $2(4.1)$ & $2(4.0)$ & $4(4.0)$ \\
Inattentive & $10(20.8)$ & $8(16.0)$ & $18(18.2)$ \\
Comorbid conditions $n$ (\%) & $2(4.1)$ & $3(6.0)$ & $5(5.1)$ \\
Depression & $11(22.4)$ & $9(18.0)$ & $20(20.2)$ \\
Oppositional/defiant disorder & $6(12.2)$ & $8(16.0)$ & $14(14.1)$ \\
Tics (any type) & $6(12.2)$ & $8(16.0)$ & $14(14.1)$ \\
Motoric tics & $4(8.2)$ & $7(14.0)$ & $11(11.1)$ \\
Phonetic tics & & & \\
\hline
\end{tabular}

There were no statistically significant between-group differences for any characteristics at baseline

$N$ total number of patients, $n$ number of patients with available data, $S D$ standard deviation

of the dose within the dose range of $0.5-1.2 \mathrm{mg} / \mathrm{kg}$ day was allowed for side effect control). Three patients were not compliant (i.e. $<70$ or $>130 \%$ of the prescribed study drug was taken) with the dosing regimen (one atomoxetine patient at week 10, one placebo patient at weeks 3 though 10 , and another placebo patient at week 10).

\section{Efficacy results}

Mean ADHD-RS scores at baseline were similar for both treatment groups. At endpoint, the ADHD-RS total score had improved with atomoxetine (lsmean change from baseline: -19.0$)$ and to a lesser extent with placebo (lsmean change: -6.3 ) (Table 2). This difference between treatments as well as the betweentreatment differences in the change from baseline to endpoint for the inattention and hyperactivityimpulsivity subscale scores were statistically significant in favor of atomoxetine (all $P<0.001$ ).

Analysis of the CGI scores confirmed the statistically significant superior efficacy of atomoxetine over placebo seen in the ADHD-RS total and sub-scores. An improvement from baseline to endpoint in the CGI-S score was observed in the atomoxetine group with an lsmean change of -1.8 , whereas in the placebo group the score changed only slightly $(-0.3)$. This betweentreatment difference of -1.5 points at endpoint was statistically significant $(P<0.001)$ (Table 2$)$. Similarly, the difference between atomoxetine and placebo in CGI-I was also statistically significant at endpoint in favor of atomoxetine (lsmean of 2.3 vs. 3.7; $P<0.001$; Table 2).

Results from the MMRM analyses showed that the mean ADHD-RS total scores decreased (improved) at each visit during study period II with both treatments (Fig. 2). However, in the atomoxetine group, decreases were larger between visits compared with placebo, and the most pronounced decrease occurred during the first 3 weeks. As a result, the difference between treatments in the ADHD-RS total score was statistically significant at each visit $(P<0.001)$ from visit 4 (week 3 ) onwards. This was also reflected in the corresponding ES of atomoxetine compared with placebo in the ADHD-RS total score, which increased at each visit and reached a value of 1.3 at week 10 , the end of study period II (Fig. 2).

The proportion of patients responding to treatment, defined a priori as a $\geq 25$ or $\geq 40 \%$ improvement from baseline to endpoint of the ADHD-RS total score, were considerably higher among atomoxetine patients [35 patients $(71.4 \%)$ and $31(63.3 \%)]$ than

Table 2 Scores for the assessment of the ADHD core symptoms at baseline and changes from baseline to endpoint

\begin{tabular}{|c|c|c|c|c|c|c|}
\hline & \multirow{2}{*}{\multicolumn{2}{|c|}{$\frac{\text { Baseline score }}{\text { Mean (SD) }}$}} & \multicolumn{4}{|l|}{ Change from baseline $^{a}$} \\
\hline & & & \multicolumn{2}{|l|}{ LS mean (SE) } & \multicolumn{2}{|c|}{ Difference in LS means } \\
\hline & Atomoxetine $(N=49)$ & Placebo $(N=50)$ & Atomoxetine $(N=49)$ & Placebo $(N=50)$ & Estimate $(95 \% \mathrm{Cl})$ & $P$-value \\
\hline \multicolumn{7}{|l|}{ ADHD-RS Score } \\
\hline Total & $38.9(7.7)$ & $39.5(6.7)$ & $-19.0(1.5)$ & $-6.3(1.5)$ & $-12.8(-16.8 ;-8.8)$ & $<0.001$ \\
\hline Inattention subscale & $21.3(4.1)$ & $21.5(3.7)$ & $-10.3(0.8)$ & $-3.8(0.7)$ & $-6.5(-8.6 ;-4.5)$ & $<0.001$ \\
\hline Hyperactivity-impulsivity subscale & $17.6(6.4)$ & $18.0(5.9)$ & $-8.7(0.8)$ & $-2.5(0.8)$ & $-6.2(-8.5 ;-4.0)$ & $<0.001$ \\
\hline CGI-Severity & $4.8(0.7)$ & $4.9(0.7)$ & $-1.8(0.1)$ & $-0.3(0.1)$ & $-1.5(-1.9 ;-1.1)$ & $<0.001$ \\
\hline CGI-Improvement $^{\mathrm{a}}$ & - & & $2.3(0.2)$ & $3.7(0.2)$ & $-1.4(-1.8 ;-1.0)$ & $<0.001$ \\
\hline
\end{tabular}

$N$ total number of patients, SD standard deviation, $L S$ least square, $S E$ standard error, $C I$ confidence interval, CGI clinical global impression

${ }^{\mathrm{a}}$ For CGI-improvement values at endpoint are given which reflect the change from baseline as defined by the instrument $(1=$ very much improved; ...; $4=$ no change; ...; 7 = very much worsened) 


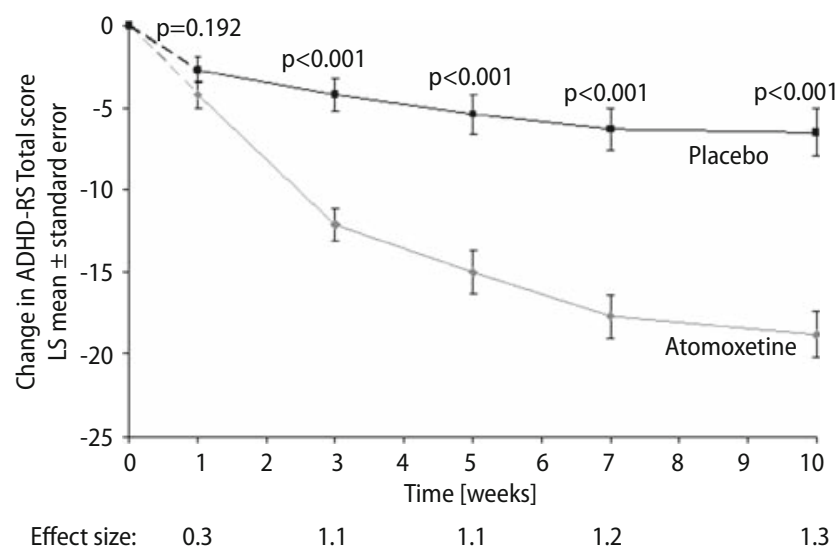

Fig. 2 Change from baseline in ADHD-RS total score--repeated measures least square (LS) means ( $P$-values are for the between-treatment comparison at the indicated time point) and ESs

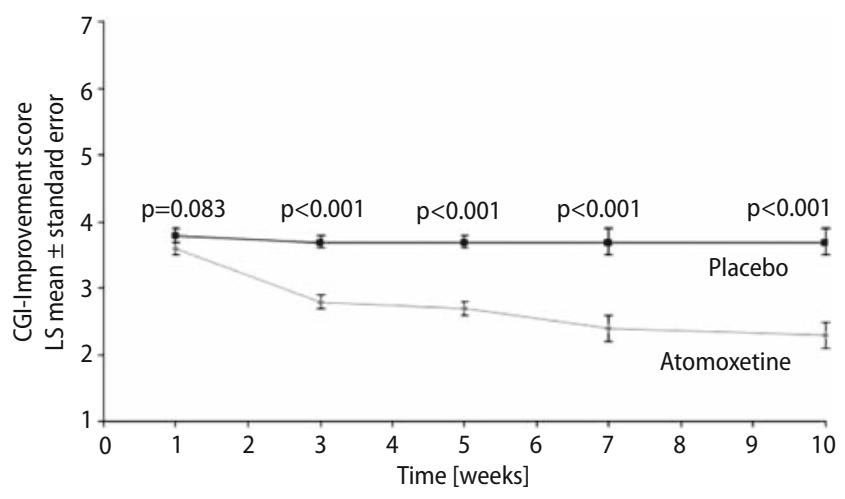

Fig. 3 CGI-Improvement score--repeated measures least square (LS) means (given $P$-values are for the between-treatment comparison at the indicated time point)

among placebo patients [14 (28.6\%), 7 (14.3\%); $P<0.001$ for both treatment comparisons].

Results from the repeated measures analysis of the CGI-I were similar to those seen in the ADHD-RS, with statistically significant between-treatment differences in favor of atomoxetine at each visit $(P<0.001)$ from visit 4 (week 3 ) onwards (Fig. 3). In contrast to a continued improvement in the atomoxetine group, the CGI-I score in the placebo group did not show any further improvement after its first assessment at visit 3 (week 1).

\section{Evaluation of parental psychoeducation}

The global parental assessment of most aspects of psychoeducation was very positive. Items were mostly rated as "very good/very satisfied" or "rather good/ satisfied" (in the absolute majority of assessments, including questions about increased knowledge on the disorder, ways of coping with it, and how to prevent problematic behavior). Regarding questions about the change of the children's functioning, the majority of parents still noted an improvement, although the proportion of more negative answers was higher. The evaluation was not monitored by the study sponsor, and therefore no absolute numbers are presented here.

\section{Safety results}

Treatment with atomoxetine was well tolerated. No patients discontinued during the double-blind treatment phase. Forty-four patients $(89.8 \%)$ on atomoxetine and 37 patients $(74.0 \%)$ on placebo reported one or more AEs $(P=0.066)$. The most common AEs reported for atomoxetine-treated patients were headache, abdominal pain upper, fatigue, anorexia, and nausea (Table 3 ). With the exception of fatigue, proportions of patients with these AEs were statistically significantly higher in the atomoxetine group than in the placebo group. There were no statistically significant differences between treatment groups regarding the incidence for other AEs. The AEs reported with a frequency of $\geq 5 \%$ in the atomoxetine group were in line with the atomoxetine SPC [10]. No serious AEs were reported during study period II.

Mean changes from baseline to endpoint of study period II in systolic blood pressure were $1.4 \mathrm{mmHg}$ for atomoxetine and $0.3 \mathrm{mmHg}$ for placebo. Corresponding mean changes in diastolic blood pressure were $2.0 \mathrm{mmHg}$ for atomoxetine and $-1.8 \mathrm{mmHg}$ for placebo. Mean changes from baseline to endpoint in

Table 3 Adverse events reported for $\geq 5 \%$ of patients in any treatment group

\begin{tabular}{|c|c|c|c|c|}
\hline \multirow[t]{2}{*}{ Preferred term } & \multicolumn{3}{|c|}{ Number (\%) of patients } & \multirow[t]{2}{*}{$P$-value } \\
\hline & $\begin{array}{l}\text { Atomoxetine } \\
(N=49)\end{array}$ & $\begin{array}{l}\text { Placebo } \\
(N=50)\end{array}$ & $\begin{array}{l}\text { Total } \\
(N=99)\end{array}$ & \\
\hline Patients with $\geq 1$ TEAE & $44(89.8)$ & $37(74.0)$ & $81(81.8)$ & 0.066 \\
\hline Patients with no TEAE & $5(10.2)$ & $13(26.0)$ & $18(18.2)$ & \\
\hline Headache & $19(38.8)$ & $9(18.0)$ & $28(28.3)$ & 0.026 \\
\hline Abdominal pain upper & $20(40.8)$ & $7(14.0)$ & $27(27.3)$ & 0.003 \\
\hline Fatigue & 16 (32.7) & $9(18.0)$ & $25(25.3)$ & 0.109 \\
\hline Anorexia & $17(34.7)$ & $0(0.0)$ & $17(17.2)$ & $<0.001$ \\
\hline Nausea & $14(28.6)$ & $2(4.0)$ & $16(16.2)$ & $<0.001$ \\
\hline Vomiting & $6(12.2)$ & $4(8.0)$ & $10(10.1)$ & 0.524 \\
\hline Irritability & $6(12.2)$ & $2(4.0)$ & $8(8.1)$ & 0.159 \\
\hline Depressive symptom & $5(10.2)$ & $2(4.0)$ & $7(7.1)$ & 0.268 \\
\hline $\begin{array}{l}\text { Upper respiratory } \\
\text { tract infection }\end{array}$ & $5(10.2)$ & $2(4.0)$ & $7(7.1)$ & 0.268 \\
\hline Pyrexia & $2(4.1)$ & $3(6.0)$ & $5(5.1)$ & $>0.999$ \\
\hline Abdominal pain & $3(6.1)$ & $1(2.0)$ & $4(4.0)$ & 0.362 \\
\hline Decreased appetite & $3(6.1)$ & $0(0.0)$ & $3(3.0)$ & 0.117 \\
\hline Nasopharyngitis & $0(0.0)$ & $3(6.0)$ & $3(3.0)$ & 0.242 \\
\hline
\end{tabular}

$N$ total number of patients, TEAE treatment-emergent adverse event 
heart rate were 4.6 beats/min for atomoxetine and 0.8 beats/min for placebo.

\section{Discussion}

This randomized, placebo-controlled study was the first to investigate efficacy and safety of atomoxetine in a population of only stimulant-naïve patients. Another uncommon feature of the study design were the four parental psychoeducational group sessions for the patients' caregivers. The results confirmed the findings from previous trials, supporting atomoxetine as efficacious treatment of ADHD. The lsmean change of the total ADHD-RS score from baseline to endpoint for atomoxetine and psychoeducation was -19.0 versus -6.3 for placebo and psychoeducation. The mean CGI-I at endpoint was 2.3 for atomoxetine versus 3.7 for placebo, signifying that atomoxetinetreated patients were assessed, on average, as between "minimally improved" and "much improved" compared with an assessment of "no change" to "minimally improved" for placebo-treated patients. Almost two-thirds $(63 \%)$ of atomoxetine-treated patients were responders with an ADHD symptom improvement from baseline to endpoint of $\geq 40$ and $71 \%$ were responders with an improvement of $\geq 25 \%$. The atomoxetine treatment was well tolerated, and no discontinuations occurred during the double-blind study period II. The ES for the investigator-rated ADHD-RS total score was 1.3 , which was considerably higher than the previously published average ES across 11 investigator-rated atomoxetine trials (ES of 0.7) and LOCF ESs of $0.6-0.8$ in an overview of six other atomoxetine trials $[24,25]$.

The proportion of stimulant-naïve patients has been shown to positively influence treatment response [25]. In line with this observation, the ES in a subset of atomoxetine-treated stimulant-naïve patients was about 0.4 units higher than in previously stimulanttreated patients (ES of 0.9 vs. 0.5); similarly, OROS methylphenidate-treated patients improved more if they had been stimulant-naïve before than if they had been stimulant-treated (ES of 1.0 versus 0.8 ) [26]. Thus, inclusion of only stimulant-naïve patients in the present study probably reduced the study population's treatment resistance compared to other studies.

Response to atomoxetine also increases with exposure to treatment and therefore might be more a function of time than of dose [25]. In the present study, atomoxetine-treated patients continued to improve throughout the full study period of 10 weeks, even though the main reduction of symptoms occurred during the first 3 weeks. Placebo-treated patients showed very little improvement beyond this 3-week time point. At endpoint, the lsmean decrease in the ADHD-RS score for placebo-treated patients was 6.3 points, a change very similar to that seen in other placebo-controlled atomoxetine trials that did not include concomitant psychoeducation: In five of six placebo-controlled studies, each with a duration of 6-9 weeks and using investigator-rated ADHD-RS, the mean change in the placebo-treated group varied between 5.5 and 7.0 points [11-14], whereas corresponding decreases in mean ADHD-RS scores in the atomoxetine-treated groups of these studies varied between 12.8 and 16.7 points; however, this was still well below the lsmean reduction of 19.0 points observed in the present study.

The absence of any premature discontinuations in study period II, which presumably was at least in part a result of the prospect of receiving atomoxetine in study period III, might have added to the high ES. The null attrition rate and the very high treatment compliance of the study, in combination with the ADHD-RS changes in both treatment groups, support the assumption that parental psychoeducation interacts positively with active pharmacological treatment rather than being an efficient add-on-treatment of ADHD per se, at least during the relatively short time period of 10 weeks. This was supported by the results of the parents' evaluation of psychoeducation. Regretfully, the study design did not allow for matching the responses of the parents' evaluation to the treatment of the respective child. Nevertheless, the absolute majority of parents appreciated receiving more knowledge about ADHD and getting new insights of more adaptive ways of coping with their children. Simultaneously, a substantial number of parents still perceived their children's ADHD symptoms as very little or not improved at all.

The relative importance of active pharmacological treatment compared with psychosocial interventions, at least during a similar short time-frame as in the present study, was demonstrated recently: ratings of ADHD core symptoms, oppositional and conduct behavior, parenting stress, anxiety, and self-worth improved significantly after treatment with methylphenidate alone or in combination with an intensive 10-week multimodal behavior therapy, but no significant differences were found between the outcomes of the two treatment arms [27]. Similarly, no difference in outcome between medication-only and medication combined with intensive multimodal therapy was observed in the MTA study, which compared four treatment arms (medication with methylphenidate only, intensive multimodal therapy only, a combination of both, and standard community care) over a longer time period of 14 months [28]. However, parents preferred both conditions including behavioral treatments over the medication-only arm, and the combined treatment had the highest pro- 
portion of "excellent" responders [28, 29]. Thus, the increased parental knowledge and awareness of the disease and its pharmacological treatment might result in increased treatment compliance, providing a possible synergy between pharmacological treatment and psychoeducation. Positive effects on treatment compliance, parenting skills, and confidence were described in two uncontrolled studies reporting of psychoeducational interventions similar to those in the present study [30,31]. In addition, good compliance has another statistical implication, as particularly early drop-outs, analyzed using the LOCF principle, tend to introduce a bias for the change from baseline to endpoint since their baseline scores are projected to the endpoint.

ADHD is a disorder characterized by a very high prevalence of comorbid conditions [29, 32], the most common being oppositional defiant disorder (ODD), occurring in $40-60 \%$ of children with the ADHD, and conduct disorder (CD) in $14 \%$ of pediatric ADHD patients $[29,33]$. In the present study, the proportion of patients with comorbid ODD was lower $(20 \%)$ than in many other atomoxetine trials (33-46\%) [34], and no patient fulfilled diagnostic criteria for $\mathrm{CD}$. This low prevalence of comorbid diagnoses was probably a consequence of excluding patients requiring immediate pharmaco- and/or psychotherapy. The existing data concerning the impact of comorbid ODD on treatment outcome in ADHD are somewhat contradictory. Generally, ODD has been associated with a greater number of ADHD symptoms, increased ADHD severity, and a poorer prognosis $[35,36]$. However, a similar treatment response of pediatric patients with and without comorbid ODD has also been reported, although comorbid patients needed higher atomoxetine doses (1.8 mg/kg day) [37]. Thus, since the present study complied with the approved EU dosing (maximum dose around $1.2 \mathrm{mg} / \mathrm{kg}$ day), the relatively low proportion of comorbid ODD patients may also have contributed to the high ES of the study.

Anxiety disorders represent another ADHD comorbidity that may impact treatment response [28, 32]. So far, the highest reported ES in any published atomoxetine trial has been achieved in a study population with ADHD and comorbid anxiety disorders (ES of 1.0) [38]. The prevalence of anxiety syndromes (except for simple phobias) was as high as $34 \%$ in the MTA study [29]. In contrast, the prevalence of anxiety disorders in four North American and Non-North American atomoxetine studies $(N=1,269)$, in which the same diagnostic procedure (K-SADS-PL [20]) was used as in the present trial, were not higher than 0.5-
$2.3 \%$ [34]. Unfortunately, no systematic screening for comorbid anxiety disorders was performed in the present study. It is therefore not possible to evaluate the possible effect of comorbid anxiety on the ES, which is one obvious limitation of this study.

The exclusion of patients with need of immediate symptom relief represents another limitation, as it probably resulted in a study population that was not fully representative for treatment-naïve ADHD patients in Sweden. It's even probable that investigators to some degree preferentially enrolled patients they expected to benefit from atomoxetine rather than from treatment with stimulants, which represented the only approved pharmacological treatment at the time the study was run. However, this as well might be regarded a concurrent advantage of the study, since the results provide an empirically based picture of atomoxetine, given as "first-line" treatment, in combination with parental psychoeducation.

With regards to safety, atomoxetine was well tolerated and did not cause any serious AEs or premature discontinuations. The safety profile was in line with the profile known from other atomoxetine studies and consistent with the label for atomoxetine. A significantly higher incidence among atomoxetine patients compared to placebo patients was observed for the AEs headache, abdominal pain upper, anorexia, and nausea.

\section{Conclusions}

This is the first published study comparing only stimulant-naïve ADHD patients treated with atomoxetine or placebo in combination with concurrent parental psychoeducation. Potentially, psychoeducation was the reason for improved treatment compliance both in placebo- and atomoxetine-treated patients, in spite of significant parental recognition of limited or absent treatment response in about half of the patients. No patients discontinued the study. Inclusion of only treatment-naïve patients and patients who, in the opinion of the investigator, were more likely to respond to atomoxetine than to stimulants, may have added to the superior efficacy of atomoxetine treatment over placebo. The 10-week duration of the double-blind study period, which was long enough for the full treatment effect of atomoxetine to develop, may also have contributed to the good efficacy. Atomoxetine treatment was well tolerated with a safety profile in line with the current label. 
Acknowledgments This research was funded by Eli Lilly Sweden AB. Hamid Bakhshi, former team leader CNS Eli Lilly Sweden AB, for support, encouragement and technical expertise. Ansgar Dressler and Dr. Birgit von Janowsky, Trilogy Writing \& Consulting GmbH, Frankfurt, Germany for their help with preparation of this manuscript. Agneta Hellström, currently Director, ADHD-Center, Stockholm Habilitation Services, for managing the study parental educational program, and for educating the supervisors of the study sites. Asa Nylen, former Clinical Research Associate (CRA) and in charge of the study operations, currently Medical liason
CNS, Eli Lilly Sweden AB. Alexander Schacht, Eli Lilly Deutschland $\mathrm{GmbH}$, for statistical help during the preparation of the manuscript. The following investigators participated in the study: Bernt Danielsson, M.D. (Mölnlycke), Lennart Eriksson, M.D. (Orebro), Peter Gottfarb, M.D. (Huddinge), Christina Högström, M.D. (Lund), Mats Johnson, M.D. (Göteborg), Eva Norén, M.D. (Uppsala), Tatjana Olofsson, M.D. (Umeå), Aivar Päären, M.D. (Örebro), Mats Reimer, M.D. (Mölnlycke). Authors Per A Gustafsson, M.D., Ph.D., Bruno Hägglöf, M.D., Ph.D., Björn Kadesjö, M.D., Ph.D., and Gunilla Thernlund, M.D., Ph.D., were also investigators.

\section{References}

1. American Psychiatric Association (2000) Diagnostic and statistical manual of mental disorders: DSM-IV-TR, Washington

2. Remschmidt H, Global ADHD Working Group (2005) Global consensus on ADHD/HKD. Eur Child Adolesc Psychiatry 14(3):127-137

3. Biederman J, Faraone SV, Milberger S, Guite J, Mick E, Chen L, Mennin D, Marrs A, Ouellette C, Moore P, Spencer T, Norman D, Wilens T, Kraus I, Perrin J (1996) A prospective 4-year follow-up study of attention-deficit hyperactivity and related disorders. Arch Gen Psychiatry 53:437-446

4. Gillberg C, Kadesjo B (2003) Why bother about clumsiness? The implications of having developmental coordination disorder (DCD). Neural Plast 10(1-2):59-68

5. Goldman LS, Genel M, Bezman RJ, Stanetz PJ (1998) Diagnosis and treatment of attention-deficit/hyperactivity disorders in children and adolescents. JAMA 279:1100-1107

6. Biederman J, Monuteaux MC, Mick E, Spencer T, Wilens TE, Silva JM, Snyder LE, Faraone SV (2006) Young adult outcome of attention deficit hyperactivity disorder: a controlled 10-year follow-up study. Psychol Med 36(2): 167-179

7. Biederman J, Faraone SV (2005) Attention-deficit/hyperactivity disorder. Lancet 366:237-248

8. Escobar R, Soutullo CA, Hervas A, Gastaminza X, Polavieja P, Gilaberte I (2005) Worse quality of life for children with newly diagnosed attention-deficit/ hyperactivity disorder, compared with asthmatic and healthy children. Pediatrics 116:364-369

9. Bernet W, Dulcan MK, Greenhill LL, Pliszka SR (2004) AACAP-endorsed managing: attention-deficit/hyperactivity disorder. Guidelines (pocketcard) version 2.0 American academy of child and adolescent psychiatry. International guidelines center. Available at: http://www.myguidelinescenter.com
10. UK Strattera SPC (2007)

11. Kelsey D, Sumner C, Casat C, Coury DL, Quintana H, Saylor KE, Sutton VK, Gonzales J, Malcolm SK, Schuh KJ, Allen AJ (2004) Once-daily atomoxetine treatment for children with attention-deficit hyperactivity disorder, including an assessment of evening and morning behavior: A double-blind, placebo-controlled trial. Pediatrics 114(1):e1-e8

12. Michelson D, Allen AJ, Busner J, Casat C, Dunn D, Kratochvil C, Newcorn J, Sallee FR, Sangal RB, Saylor K, West S, Kelsey D, Wenicke J, Trapp NJ, Harder D (2002) Once-daily atomoxetine treatment for children and adolescents with attention deficit hyperactivity disorder: a randomized, placebo-controlled study. Am J Psychiatry 159: 1896-1901

13. Michelson D, De Faires, Wenicke J, Kelsey DK, Kendrick KL, Sallee FR, Spencer $\mathrm{T}$, Atomoxetine ADHD Study Group (2001) Atomoxetine in the treatment of children and adolescents with ADHD: a randomized, placebo-controlled doseresponse study. Pediatrics 108:e83

14. Spencer T, Heiligenstein JH, Biederman J, Faries DE, Kratochvil CJ, Conners CK, Potter WZ (2002) Results from 2 proof-of-concept, placebocontrolled studies of atomoxetine in children with attention-deficit/hyperactivity disorder. J Clin Psychiatry 63:1140-1147

15. Weiss M, Tannock R, Kratochvil C, Dunn D, Velez-Borras J, Thomason C, Tamura R, Kelsey D, Stevens L, Allen AJ (2005) A randomized, placebo-controlled study of once-daily atomoxetine in the school setting in children with ADHD. J Am Acad Child Adolesc Psychiatry 44(7):647-655

16. Mosholder AD (2006) Psychiatric adverse advents in attention-deficit/ hyperactivity disorder (ADHD) clinical trials. Food and Drug Administration, Pediatric Advisory Committee, 22 March, 2006. Available at: http:// www.fda.gov/ohrms/dockets/AC/06/ slides/2006-4210s_14_Mosholder_PsychiatricAdverse Events_files/frame.htm
17. Riley AW, Forrest CB, Starfield B, Rebok GW, Robertson JA, Green BF (2004) The parent report form of the CHIP-child edition: reliability and validity. Med Care 42(3):210-220

18. RileyAW, Coghill D, Forrest CB, Lorenzo MJ, Ralston SJ, Spiel G (2006) Validity of the health-related quality of life assessment in the ADORE study: parent report form of the CHIP-child edition. Eur Child Adolesc Psych 15(Suppl 1):1/63-1/71. doi:10.1007/ s00787-006-1009-6

19. Weiss MD, Virani A, Wasdell M, Faulkner M, Rea K, Freeman RD, Weiss G, Jokhani V (2006) Atomoxetine in clinical practice. Future Neurol 1(3): 249-258

20. Kaufman J, Birmaher B, Brent D, Rao U, Flynn C, Moreci P, Williamson D, Ryan N (1997) Schedule for affective disorders and schizophrenia for school-age children-present and lifetime version (K-SADS-PL): initial reliability and validity data. J Am Acad Child Adolesc Psychiatry 36(7):980-989

21. DuPaul GJ, Power TJ, Anastopoloulos AD, Reid R (1998) ADHD rating scaleIV checklist, norms and clinical interpretation. The Guilford Press, New York

22. Faries DE, Yalcin I, Harder D, Heiligenstein JH (2001) Validation of the ADHD rating scale as a clinician administered and scored instrument. J Atten Disord 5:39-47

23. Guy W (1976) ECDEU assessment manual for psychopharmacology. Rockville: National Institute of Mental Health (NIMH), Psychopharmacology Research Branch (revised 1976)

24. Banaschewski T, Coghill D, Santosh P, Zuddas A, Asherson P, Buitelaar J, Danckaerts M, Döpfner M, Faraone SV, Rothenberger A, Sergeant J, Steinhausen H-C, Sonuga-Barke EJS, Taylor E (2006) Long-acting medication for the hyperkinetic disorders. A systematic review and European treatment guidelines. Eur Child Adolesc Psychiatry. doi:10.1007/s00787-006-0549-0 
25. Sutton VK, Milton DR, Ruff DD, Allen AJ (2004) Atomoxetine's efficacy over time in children and adolescents with attention-deficit/hyperactivity disorder. In: Poster presented at AACAP, Washington, 19-24 October, 2004

26. Newcorn JH, Kratochvil CJ, Allen AJ, Milton DR, Moore R, Michelson D (2005) Atomoxetine and OROS methylphenidate for the treatment of ADHD: acute results and methodological issues. In: Poster presented at NCDEU

27. van der Oord S, Prins PJM, Oosterlaan J, Emmelkamp PMG (2007) Does brief, clinically based, intensive multimodal behavior therapy enhance the effects of methylphenidate in children with ADHD? Eur Child Adolesc Psychiatry 16:48-57

28. MTA Cooperative Group (1999) Moderators and mediators of treatment reponse for children with attentiondeficit/hyperactivity disorder. Arch Gen Psych 56:1088-1096

29. MTA Cooperative Group (1999) A 14 month randomized clinical trial of treatment strategies for attention-deficit/hyperactivity disorder. Arch Gen Psych 56:1073-1086
30. McLeary L, Ridley T (1999) Parenting adolescents with ADHD: evaluation of a psychoeducation group. Parent Education Councelling 38:3-10

31. Monastra VJ (2005) Overcoming the barriers to effective treatment for attention-deficit/hyperactivity disorder: a neuron-educational approach. Int J Psychophysiol 58:71-80

32. Jensen PS, Martin D, Cantwell DP (1997) Comorbidity in ADHD: implications for research, practice, and DSM-V. J Am Child Adolesc Psychiatry 36:1065-1079

33. August GJ, Realmuto GM, MacDonald AW 3rd, Nurent SM, Crosby R (1996) Prevalence of ADHD and comorbid disorder among elementary children screened for disruptive behavior. J Abnorm Child Psychol 24:571-595

34. Buitelaar JK, Barton J, Danckaerts M, Friedrichs E, Gillberg C, Hazell PL, Hellemans H, Johnson M, Kalverdijk LJ, Masi G, Michelson D, Revol O, Sebastian JS, Zhang S, Zuddas A (2006) A comparison of North American versus non-North American ADHD study populations. Eur Child Adolesc Psychiatry 15:177-181
35. Greene RW, Biederman J, Zerwas S, Monuteaux MC, Goring JC, Faraone SV (2002) Psychiatric comorbidity, family dysfunction, and social impairment in referred youth with oppositional defiant disorder. Am J Psychol 159:12141224

36. Kuhne M, Schachar R, Tannock R (1997) Impact of comorbid oppositional or conduct problems on attention-deficit hyperactivitiy disorder. J Am Acad Child Adolesc Psychiatry 36:1715-1725

37. Newcorn JH, Spencer TJ, Biederman J, Milton DR, Michelson D (2005) Atomoxetine treatment in children and adolescents with attention-deficit/ hyperactivity disorder and comorbid oppositional defiant disorder. J Am Acad Child Adolesc Psychiatry 44: 3240-3248

38. Geller D, Donnelly C, Lopez F, Rubin R, Newcorn J, Sutton V, Bakken R, Paczkowski M, Kelsey D, Sumner C (2007) Atomoxetine treatment for pediatric patients with attention-deficit/hyperactivity disorder with comorbid anxiety disorder. J Am Acad Child Adolesc Psychiatry 46(9):1119-1127 